\title{
La "multimidad": performances íntimas en Facebook de adolescentes de Buenos Aires
}

\author{
Joaquín Linne \\ CONICET, Universidad de Buenos Aires, Universidad Nacional de Lanús \\ joaquinlinne@gmail.com
}

\section{Resumen}

Este artículo aborda las performances de intimidad que despliegan los adolescentes de la Ciudad de Buenos Aires mediante la red social Facebook. La metodología utilizada consiste en una etnografía mixta. Por un lado, la realización de observaciones copresenciales y de 30 entrevistas en profundidad a adolescentes del universo de estudio. Por otro, análisis de imágenes a partir de fotos personales, dada la centralidad que tiene este recurso para la población mencionada. Entre los resultados se describen las performances que publican y comentan de modo cotidiano los adolescentes indagados. El principal aporte es la proposición del concepto "multimidad" para dar cuenta de los modos en que ellos construyen y comparten su intimidad mediante la plataforma.

Palabras clave: adolescentes, Facebook, performance, intimidad, Buenos Aires.

Abstract

\section{"Multimity": intimate performances from adolescents of Buenos Aires in Facebook}

This article discusses the intimate performances that display adolescents of the City of Buenos Aires through the social network Facebook. The methodology consists of a mixed ethnography: first, conducting content analysis of thirty in-depth interviews with adolescents of the universe of study and also face-to-face and virtual observations. Among the results, daily performances that publish everyday adolescents are 
described and the concept multimity ("multimidad") is proposed to account for the ways in which they build and share their privacy in the digital platform.

Key words: adolescents, Facebook, performance, intimacy, Buenos Aires.

\section{Introducción}

La importancia que tiene el uso de internet y las tecnologías de información y comunicación (TIC) para la gran mayoría de habitantes de la Ciudad Autónoma de Buenos Aires (CABA) se evidencia en las estadísticas disponibles. Un alto porcentaje de los jóvenes de la ciudad posee acceso cotidiano a internet, y la utilizan principalmente para chatear y usar sitios de redes sociales, en particular Facebook (FB) (INDEC, 2012; Morduchowicz, 2012).

Dentro de este contexto, uno de los recursos comunicativos más utilizados por los adolescentes de la CABA consiste en la publicación, visionado y comentario de fotos personales (Urresti, Linne y Basile, 2015). Estas imágenes pueden ser definidas como las que retratan al usuario, a sus grupos de pares o familiar, cuya especificidad radica en presentar aspectos íntimos de quien realiza la publicación personal. Debido a la importancia que los adolescentes le otorgan a este recurso estético como herramienta de interacción, en este artículo se ha optado por el análisis de dicho fenómeno. ${ }^{1}$

A partir del trabajo de campo y de las discrepancias con la noción "extimidad" formulada por Sibilia (2008), con relación a la supuesta tendencia global juvenil a espectacularizar la intimidad sin reparos, surgen algunos interrogantes. ¿Los adolescentes exponen su intimidad sin controles? ¿Publican todas las fotos que se sacan? ¿No desarrollan ninguna estrategia en los posteos de sus muros para resguardar o editar su intimidad? Alentados por estas inquietudes, el artículo se propone revisar críticamente el concepto de "extimidad" y proponer nuevas líneas de investigación sobre la subjetividad de los adolescentes a partir de la centralidad del análisis de imágenes.

En consecuencia, se postula el concepto "multimidad" para dar cuenta de los procesos de construcción de la intimidad que despliegan los adolescentes contemporáneos a partir de la masificación de las TIC. Para investigar los fenómenos tecnocomunicativos que viven los adolescentes contemporáneos, con este concepto se propone una tercera vía, lejos de la mirada apocalíptica en torno a la relación entre tecnología y juventud, pero también a distancia de las postulaciones acríticas y celebratorias de los tecnofílicos. Si la intimidad tradicional refería a la interioridad de los sujetos, nuestra

\footnotetext{
${ }^{1}$ Este artículo forma parte de la investigación realizada para la tesis doctoral (Linne, 2015).
} 
hipótesis es que esta nueva "multimidad" resulta una de las esferas visibles de las transformaciones entre lo privado y lo público.

\section{Metodología}

La metodología utilizada en esta investigación toma un objeto de estudio situado en la encrucijada de varias disciplinas, por lo que se denomina "etnografía mixta". ${ }^{2}$ Este cruce de técnicas obedece al objetivo de describir y analizar un caso práctico de una población específica. A nivel territorial, la investigación fue desarrollada en la Zona Sur de la CABA, área en la que habita la mayor proporción de hogares de sectores populares de la ciudad. ${ }^{3}$ Más de un tercio, por ejemplo, no posee gas natural de red y más de la mitad de los adultos posee un nivel educativo menor al de secundario completo (INDEC, 2010).

A nivel temporal, las coordenadas corresponden a 2010-2014. Tanto las entrevistas (30) como las observaciones se llevaron a cabo en colegios, centros de inclusión digital, cibercafés y vía pública. Con una duración aproximada de cincuenta minutos, las entrevistas se estructuraron a partir de una serie de preguntas que giraban en torno a las prácticas, los sentidos y las apropiaciones de las TIC en torno a la intimidad. Las preguntas no eran cerradas sino que más bien funcionaban como disparadores para la conversación. Para establecer el número necesario de observaciones y entrevistas de la muestra intencional, se utilizó el criterio de saturación de la información.

Esta investigación incorpora elementos de distintas escuelas etnográficas, desde la antropología participante (Cassell y Symon, 1994) hasta la ciberetnografía (Farquhar, 2009) y la etnografía virtual (Hine, 2000; Mayans i Planells, 2002; Ardèvol y San Cornelio, 2007; Boyd, 2008; 2014; Moya y Vázquez, 2010). Con etnografía virtual, Hine (2000) se refiere a la etnografía desarrollada en internet, cuyo trabajo de campo se basa fundamentalmente en la observación participante de webs. Debido a que la vida social se va digitalizando, la investigación social también debe hacerlo, ya que los mundos offline y online se encuentran cada vez más entrelazados (Boyd, 2014). Hace 2000).

${ }^{2}$ Con "etnografía mixta" se alude al cruce de la etnografía copresencial y la virtual (Hine,

${ }^{3}$ La importancia de investigar a los adolescentes de sectores populares radica en que se trata de una población que suele ser homologada - y por tanto en cierto modo invisibilizadaentre el gran conjunto de adolescentes, cuya descripción suele corresponder a la de los sectores medios-altos. Esta investigación explora las prácticas que realiza este grupo social en su vida cotidiana y que representan un área de relativa vacancia para el campo de las ciencias sociales. 
cinco años, Ardèvol y Estalella (2009) advertían acerca de la importancia de internet para los estudios etnográficos.

Los primeros estudios etnográficos de Internet mostraron que las interacciones mediadas por Internet eran socialmente significativas y estaban cargadas de sentido para sus participantes (Hine, 2000), una condición que resultó necesaria para legitimar el estudio social de estos fenómenos ante planteamientos previos que consideraban la comunicación mediada como interacciones sociales incompletas o de segunda categoría. (Ardèvol y Estalella, 2009: 5)

En cuanto al carácter espacial o "territorial" de esta nueva práctica etnográfica, Ardèvol y San Cornelio (2007) señalan que este es un problema que surge al estudiar las prácticas mediáticas asociadas a la internet 2.0. En este punto se ha detectado otra área de vacancia: la de trabajos que combinen herramientas etnográficas copresenciales — que describan las coordenadas socioculturales, territoriales y económicas de una población- con herramientas etnográficas virtuales. Es aquí donde la presente investigación pretende realizar una primera contribución a su campo de estudios, al complementar y triangular herramientas etnográficas tradicionales con observaciones y análisis de imágenes publicadas en plataformas virtuales.

El trabajo de campo "virtual" ha sido realizado en gran medida en FB. La elección de este tipo de etnografía resultó la más conveniente en esta instancia de investigación, en la que el foco de análisis apunta a la construcción identitaria online desplegada por estos adolescentes. Como señala Boyd (2008: 75), "FB se volvió el sitio dominante de mi trabajo de campo simplemente porque este sitio domina la atención de los adolescentes".

Esta herramienta digital ha resultado fundamental para explorar los procesos de construcción identitaria y sociabilidad que los adolescentes realizan en entornos digitales. Como señalan McDermott y Roen (2012), las tecnologías digitales se están volviendo centrales para los proyectos de investigación en juventudes: a través de éstas, se obtiene información inmediata con insights que no suelen emerger en instancias copresenciales. Estas herramientas también han sido utilizadas en diversos trabajos para reclutar participantes y realizar observaciones virtuales después de entrevistarlos, como en las investigaciones de Boyd (2008), Farquhar (2009), y Pedroni, Pasquali y Carlo (2014).

Según Murthy (2008), las nuevas tecnologías se volvieron una plataforma imprevista de trabajo de campo, confirmando que la vida diaria de una gran parte del mundo cada vez se encuentra más mediada por las TIC. Este sociólogo sostiene que una equilibrada combinación de etnografía copresencial y digital otorga una mayor variedad de métodos y permite darle centralidad 
a la perspectiva de los sujetos investigados. El mayor reto, sostiene Murthy citando a Sassen (2002), es desarrollar categorías analíticas que permitan capturar las complejas imbricaciones que se despliegan entre tecnología y sociedad.

La etnografía virtual sobre la que se basa esta investigación comenzó con la creación, a inicios de 2012, de un perfil en FB, a partir del trabajo docente ad honorem realizado en el taller de computación y en clases de apoyo de lengua, literatura e inglés en el Centro de inclusión social Conviven. ${ }^{4}$ Este perfil ha sido mantenido durante casi tres años a través de un trabajo diario de observación. En la actualidad, el perfil cuenta con alrededor de 3000 contactos pertenecientes en su mayoría a adolescentes de sectores populares de la CABA.

Se han tomado recaudos para proteger la identidad de los adolescentes que conforman la muestra. En primer lugar, no se utilizan nombres ni datos personales que permitan su localización. En segundo lugar, se han difuminado - con programas de edición digital — los rostros en todas las imágenes, lo que le da al material tomado como evidencia un carácter anónimo y evita la identificación personal. A su vez, en el caso de las entrevistas se cuenta con autorización expresa de los participantes. Por otra parte, se aclara que FB es un sitio de redes sociales público que posee las condiciones de publicidad de la mayoría de estos sitios: no presenta restricciones para mayores de 13 años, dado que cualquiera mayor de esta edad puede utilizarlo; además, todos los usuarios firmaron un contrato con FB en el que aceptan que sus datos publicados estén online.

\section{Estado de la cuestión}

Eco (1968) fue el primero en plantear que siempre hubo dos posiciones con relación a la tecnología: por un lado, la "apocalíptica", que asocia los avances técnicos con la degradación de la cultura clásica, y por otro lado la "integrada", que muestra entusiasmo ante los nuevos desarrollos tecnológicos que se masifican en la sociedad. En este artículo se establece una distancia frente a este tipo de abordaje de autores contemporáneos. Mientras esta línea "apocalíptica" sostiene que los adolescentes utilizan las TIC para exhibir la intimidad y buscar relaciones sexo-afectivas superfluas, aquí se argumenta

\footnotetext{
${ }^{4}$ CONViven se encuentra ubicado en la Zona Sur de la Ciudad de Buenos Aires, en el barrio de Mataderos. Cientos de chicos de la zona - tanto de Lugano y Mataderos como de barrios aledaños - concurren a sus talleres de cultura, arte, informática, idiomas, apoyo escolar y recreación.
} 
que los recursos desplegados por estos adolescentes suelen ser calculados $\mathrm{y}$ forman parte de las diversas estrategias con las que se presentan de modo virtual.

Un referente central del estado de la cuestión que podría encuadrarse en la primera posición es Sibilia (2008), quien sostiene que los adolescentes contemporáneos exacerban y espectacularizan su intimidad ante los otros mediante internet, fenómeno que denomina "extimidad", en referencia a que se hace exterior (éxtimo) lo que antes era interno (íntimo). Tanto Sibilia como los autores que retoman su concepto suelen desatender la construcción de sentido que realizan los adolescentes a través de estas prácticas.

Desde una mirada divergente, Boyd (2014) enfatiza que la comunicación cotidiana de los adolescentes a través de sitios como FB los ha forzado a cambiar sus concepciones en torno a lo privado, al considerar la lógica de interacciones en red que propone este tipo de sitios. En este sentido, si bien sus "comunidades personales" les ayudan a desarrollar su identidad, también pueden reforzar problemáticas de género y de clase. A su vez, Pedroni, Pasquali y Carlo (2014) señalan, a partir de una muestra de jóvenes y adultos italianos, que los usuarios de FB suelen considerar a sus amigos como su audiencia, y que para esto seleccionan los aspectos de su perfil que desean mostrar ante los demás. Sin embargo, según aclaran, la interacción cotidiana de los usuarios con la plataforma ocasiona distintas tensiones y conflictos.

En un estudio reciente sobre la autopresentación en FB de mujeres brasileñas, Lins de Almeida (2014) afirma que las usuarias suelen mostrar aspectos de su intimidad de modo consensuado y calculado, en busca de obtener estatus dentro de su red de contactos. La investigadora observa un tipo de fotos particular que se repite con frecuencia, el de las mujeres junto a sus esposos o cónyuges, lo que Lins de Almeida denomina como construcción y exhibición del "capital marital".

En este artículo, para comprobar la hipótesis en torno a la "multimidad", que trata de ir más allá de la discusión entre apocalípticos e integrados, se retoman aportes de Goffman y Butler. En primer lugar, se utiliza el enfoque dramatúrgico de Goffman (1959), quien señala que las personas se presentan ante los otros como actores que efectúan performances en un escenario, y éstas son constitutivas de su identidad, en el sentido de que las acciones repetidas de cada persona se vuelven su identidad (self). En segundo lugar, se utiliza el concepto de performatividad de Butler (2005), para dar cuenta del discurso utilizado en la construcción identitaria, en todas sus dimensiones sexo-generizadas — corporales, estéticas, lingüísticas, entre otras-. Butler enfatiza que la performatividad de las performances identitarias son lo que somos, que no hay una interioridad previa u oculta que es expresada o actuada, 
sino que esas acciones tienen el carácter performativo de hacerse cuerpo y volverse identidad. A su vez, la investigadora denomina a las corporalidades vinculadas al deseo que son difundidas por los medios de comunicación masiva como los "cuerpos que importan". Tanto Goffman como Butler coinciden en que ni la identidad ni la presentación se dan de un solo modo, ni en un solo momento, sino que son procesos que se actualizan en las interacciones cotidianas.

Por otra parte, se torna necesario aclarar que la supuesta ausencia del cuerpo y de los signos sociales en internet es una de las cuestiones más discutidas por el estado de la cuestión (Turkle, 1995; Sibilia, 2008, entre otros). Esta "descorporalización" ha supuesto para numerosos investigadores que en estos espacios la interacción se efectúa con un menor grado de prejuicios y “autenticidad". No obstante, en línea con Farquhar (2009), se sostiene que el cuerpo está presente en internet a través de las "extensiones humanas" de los distintos dispositivos, y de los textos e imágenes personales que publican los usuarios.

Respecto de los antecedentes directos de esta investigación, Farquhar (2012) explora las performances que realizan en sus perfiles personales una muestra de estudiantes universitarios de Estados Unidos, y cómo estos tienden a simplificar su autopresentación para volver más legibles y legítimos sus perfiles de redes sociales. Asimismo, este autor sostiene que las relaciones sociales entre los jóvenes suelen alternar con fluidez instancias de intercomunicación digital con situaciones de copresencialidad.

En definitiva, aquí se propone a las performances como un aspecto de la identidad y a la "autopresentación" como un conjunto de técnicas y estrategias que utilizan los adolescentes para mostrarse y darse a conocer ante su red de contactos y ante los potenciales contactos que vean su biografía.

\section{Multimidad}

La red social se ha convertido en el centro de operaciones en el que estos adolescentes articulan gran parte de su sociabilidad cotidiana y de los vínculos con sus pares. Esta plataforma es su entorno central de comunicación y entretenimiento: blogs, mails y mensajería instantánea ya no aparecen como aplicaciones independientes, sino que han sido centralizadas en FB (Linne, 2014).

Los adolescentes indagados pueden ser denominados "prosumidores": actores performativos y sujetos voyeurísticos que constituyen audiencias y, al mismo tiempo, presentan "escenarios" y "actuaciones" (Urresti, Linne y Basi- 
le, 2015). Estas prácticas performativas generan conflictos en diversos entornos (familiar, escolar, sexoafectivo) y dan cuenta de las distintas concepciones de la intimidad entre adultos y adolescentes acerca de qué es válido mostrar en redes sociales, y qué es preciso reservar para el ámbito privado.

\section{Entrevistas}

A Facebook trato de entrar todos los días, siempre que puedo. Ahí están todos mis amigos y así me entero de qué le pasa a ellos; les cuento de mí y oigo de cosas que pasan en el barrio y con los vecinos. (Varón, 18 años)

En Face trato de mostrar las mejores cosas de mí. Nunca se sabe cuándo va a aparecer algún chico que me guste o algo. Igual también lo hago para que lo vean mis amigas y mis amigos. Igual que lo hace el resto. Es un ida y vuelta. Y así nos conocemos más y nos mantenemos comunicados cuando no nos vemos. (Mujer, 17 años)

Mediante FB la mayoría de los adolescentes conforman redes de contactos con los que comparten aspectos íntimos. El modo más frecuente de esta práctica es a través de fotos personales, que es posible diferenciar en dos grandes categorías: autofotos (llamadas en inglés selfies) y fotos con grupos de pares. Ambas cuentan con importantes componentes identitarios, estéticos, sexuales y lúdicos, dado que los adolescentes experimentan con su propia imagen y construyen, de modo performativo, su corporalidad mientras prueban diferentes accesorios, vestuarios y programas de edición (Linne y Basile, 2014). Al ser consultada sobre las prácticas que desarrolla en FB, una adolescente respondió:

\section{Entrevista}

Hacemos videos o sacamos fotos, por ejemplo, las editamos y las publicamos en Facebook. No hay otra cosa así. Es único y lo puede hacer cualquiera. Nosotras nos sacamos fotos en el colegio, en el shopping, cuando estamos juntas en la casa de alguna, cuando salimos. Siempre salimos con la cámara. Y aprovechamos los tiempos muertos para ver fotos que publican otros. (Mujer, 15 años)

Para los adolescentes estudiados, la centralidad de las imágenes no sólo reside en su valor para la construcción identitaria, sino también como prueba de fidelización. En este sentido, los propios adolescentes afirman valerse de la información básica, las preferencias culturales y, sobre todo, de las fotos personales para distinguir a los usuarios activos y "reales" (a quie- 
nes definen como aquellos que tienen fotos de sí mismos y son "etiquetados"5 por otros) de aquellos perfiles que les resultan "sospechosos". Estos últimos son acusados de ocultar su identidad para desarrollar posibles actividades clandestinas y en ocasiones ilegales, como spam, ciberbullying, robos, estafas y abusos.

\section{Entrevista}

Muchas veces si no tienen fotos de ellos ni posteos de su vida no los aceptamos. Porque huele raro, no se sabe quién puede ser. Sumamos contactos de desconocidos pero siempre que muestren cosas suyas: fotos con los amigos, dónde viven, esas cosas. (Mujer, 18 años)

En efecto, los usuarios menos confiables son aquellos que presentan un menor flujo de interacciones y un mayor porcentaje de comentarios negativos de la comunidad. Los usuarios nuevos - al no tener fotos, amigos, etiquetados y comentarios-, si quieren ser aceptados dentro de una red de contactos, deben dar pruebas adicionales de su identidad. Estas "autobiografías" de distintas viñetas de sus vidas cotidianas demuestran que se trata de usuarios reales y no cuentas creadas con fines potencialmente nocivos o simplemente voyeurísticos.

Las performances de autopresentación que involucran la corporalidad se masificaron primero entre las mujeres, aunque son cada vez más frecuentes entre los varones adolescentes. Esto sucede en gran medida porque ambos encuentran en FB un vehículo efectivo para exhibir sus performances íntimas y para consumir las performances de sus conocidos.

Tanto las mujeres como los varones que logran una significativa visibilidad en FB exponen una corporalidad que construyen eficazmente para agradar a una gran parte de la red de contactos. Esta corporalidad exitosa puede pensarse como los bienes efectivos o potenciales que permiten conseguir recursos (copresenciales o virtuales) mediante la valoración de la corporalidad por otros. No obstante, en el trabajo de campo se evidencia que esta práctica es meditada y que su mayor interés reside en la comunicación con sus grupos de pares, en el estar actualizado sobre las performances de intimidad que realizan ellos y sobre lo que sucede en el barrio y en el colegio.

Entre los adolescentes de la muestra, la delgadez es uno de los aspectos más valorados en la construcción de su corporalidad, así como también la

${ }^{5}$ El "etiquetado" consiste en la aplicación de etiquetas de otros usuarios sobre las fotos publicadas. De este modo, al pasar el puntero del mouse por las personas de la imagen, si están etiquetadas aparecen sus nombres. Cuando se etiqueta a alguien, se crea un enlace (link) a su perfil. 
exhibición de músculos, en el caso de los varones, y curvas en el caso de las mujeres. La gran mayoría de imágenes publicadas presentan delgadez, como si entre estos adolescentes el sobrepeso "no existiese" o fuese un tabú. Si bien en el trabajo de campo copresencial se entrevistaron y observaron a diversos adolescentes con sobrepeso, ellos no suelen publicar fotos de sus cuerpos o editan las imágenes para "disimular" aquello que no creen deseable. A diferencia de quienes presentan sobrepeso, los adolescentes delgados suelen priorizar la exhibición de una corporalidad de cuerpo entero, con el fin de acentuar su sensualidad. Esta práctica refuerza la hipótesis planteada: la intimidad no se expone sin reparos, sino como resultado de una práctica meditada y estratégica que es compartida por los pares.

Estas corporalidades compartidas virtualmente son elogiadas o criticadas en FB, tanto a través de indicar "me gusta" como de comentarios en el muro o vía chat. Para los adolescentes, que se encuentran en un periodo central de configuración identitaria (Urresti, 2012), se torna crucial la búsqueda de reconocimiento a través de la publicación de fotos personales. De este modo, las performances de intimidad que publican funcionan como "moneda de cambio". Al igual que los usuarios de foros, quienes al postear contenidos valiosos son recompensados con puntaje o crédito por otros usuarios, aquí los adolescentes que tributan performances de intimidad son premiados con la lógica del sistema FB: cientos o decenas de "me gusta" y comentarios que elevan el grado de visibilidad de su publicación dentro de su red de contactos.

En definitiva, los adolescentes utilizan la plataforma como centro de operaciones para desplegar distintas estrategias para construir su intimidad entre pares. En este contexto, expresan preocupación por su corporalidad, dado que la asocian a su éxito social. Si sus publicaciones no obtienen repercusión entre su red de contactos, tienden a sentirse poco valorados.

Lo interesante de esta población específica reside en sus estrategias para construir una intimidad entre pares que resulte atractiva aun cuando en numerosas ocasiones portan corporalidades divergentes a los ideales de belleza contemporáneos que reproduce la estética publicitaria y los medios de comunicación masiva. En este sentido, se observan fotos de primer plano de su rostro o de plano medio (de la cintura para arriba), o fragmentos de su cuerpo. Las siguientes imágenes son características entre los adolescentes de la muestra. En la imagen 1 se observa la elección de plano medio en la foto de perfil para construir su corporalidad a partir del rostro y los pechos, junto con la alusión a la marihuana en la foto de portada a través de la exhibición de un cigarrillo gigante. En la imagen 2, se ve a un adolescente con el torso desnudo apoyado en el capot de un auto y con una bebida alcohólica en la mano. 


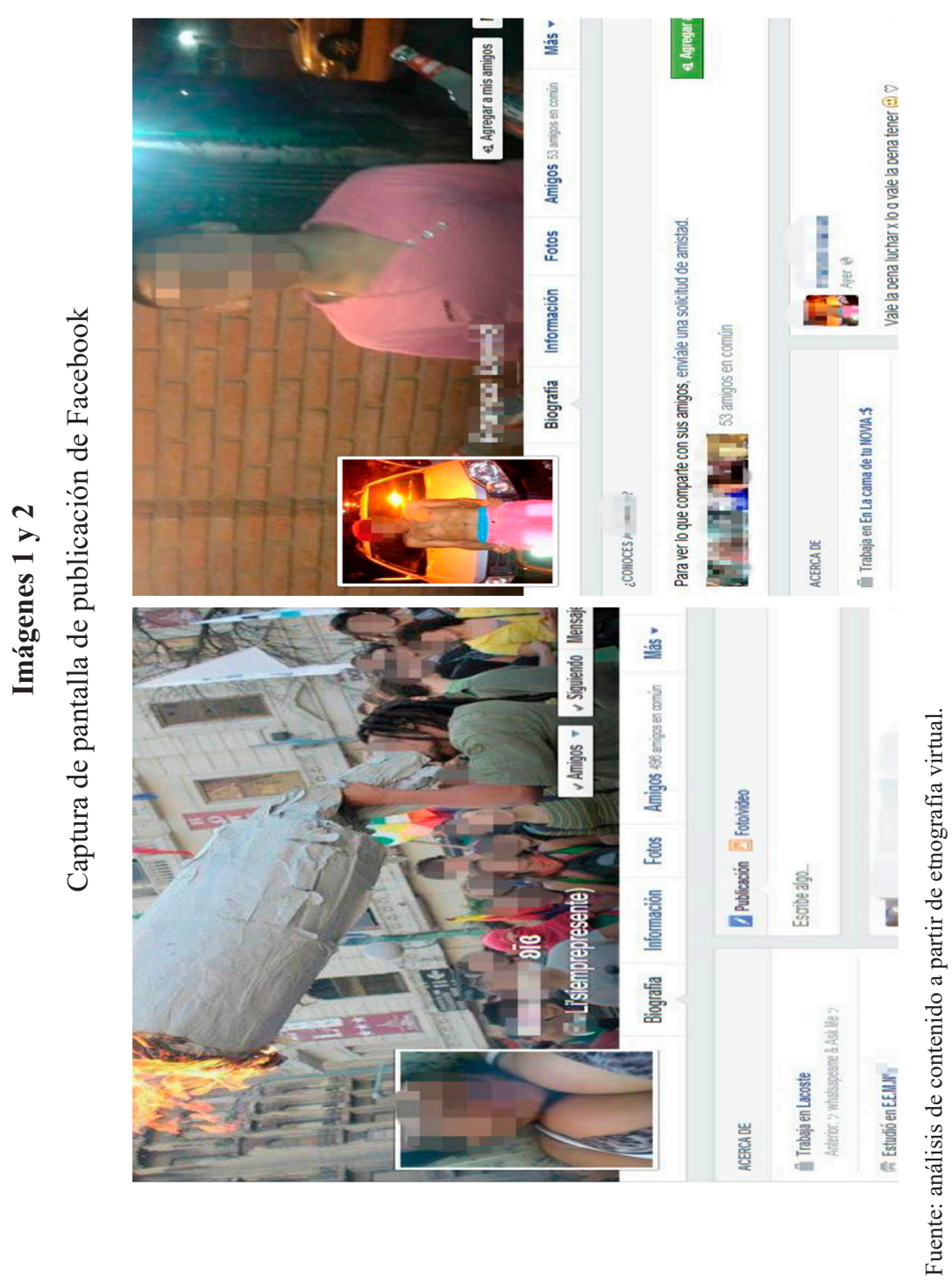


Por otra parte, los objetos con los que se fotografían funcionan como "extensiones y prótesis" de su corporalidad. Las mujeres tienden a publicar fotos personales mientras posan con sombreros, maquillaje, lentes negros, anillos, aros y piercings. Los objetos elegidos de modo unisex, en mayor medida, son el teléfono celular, la cámara de fotos y los auriculares; en menor medida, las camisetas de fútbol (Linne y Basile, 2014).

En la primera imagen anterior, resulta paradigmática la exhibición del ombligo (en ocasiones con piercings) como signo de una apropiación específica de las mujeres adolescentes de esta población. En la segunda, en la autofoto el adolescente (16 años) se presenta con la camiseta de fútbol del club de su barrio (Nueva Chicago), con una gorra y una cámara de fotos. Los adolescentes también muestran su cámara digital, su teléfono-cámara, su televisor y su computadora.

En la imagen posterior, se observa a una adolescente (17 años) presentarse en su foto de perfil con un primer plano de sí misma y del teléfono celular con el que produce la selfie; en la portada, también se presenta en plano medio y de fondo muestra su cama, su guardapolvo blanco escolar y el reproductor de DVD.

Estos dispositivos con los que realizan autofotos o fotos con el grupo de pares dan cuenta de un control sobre el front y de una construcción estratégica de las performances de intimidad, es decir, una nueva configuración que aquí se denomina "multimidad". Para esto, utilizan en sus imágenes personales los elementos que consideran más atractivos y prestigiosos. Por ejemplo, autos, motos, bebidas alcohólicas, zapatillas y ropa de marca, así como también objetos tecnológicos asociados a la comunicación, la información y el entretenimiento.

Si todas estas imágenes pueden ser leídas como el front, también es posible encontrar otras imágenes que dan indicios del backstage. En este sentido, el "escrache fotográfico"6 es una categoría nativa que refiere a una foto "espontánea" que muestra una imagen supuestamente no editada, la cual supone cierta exhibición del backstage personal aunque no deje de ser otra performance editada para publicar en el front. Puede consistir en un "autoescrache" (autofoto de un adolescente recién levantado o despeinado) o un "escrache" a un amigo (durmiendo o ebrio). En el siguiente ejemplo, una adolescente (16 años) se jacta de que se muestra "como realmente es:

${ }^{6} \mathrm{El}$ "escrache" es un término surgido del uso de agrupaciones de Derechos Humanos como HIJOS, que "escrachaban" (señalaban, marcaban) las viviendas de represores de la última dictadura militar que se encontraban sin condena. A partir de la masificación de este uso en los medios de comunicación masiva, fue apropiado por los adolescentes de la CABA con sentidos particulares. 


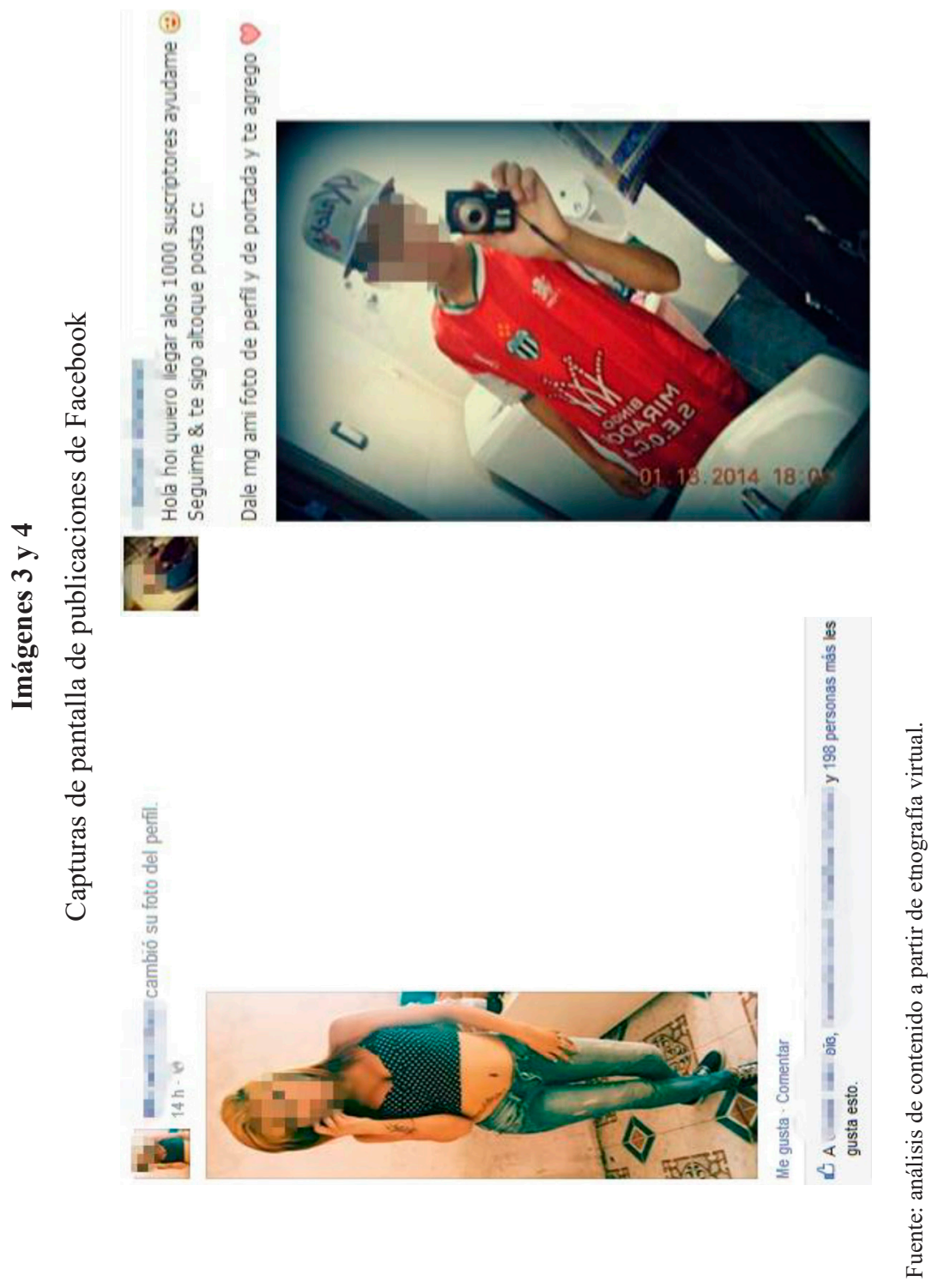




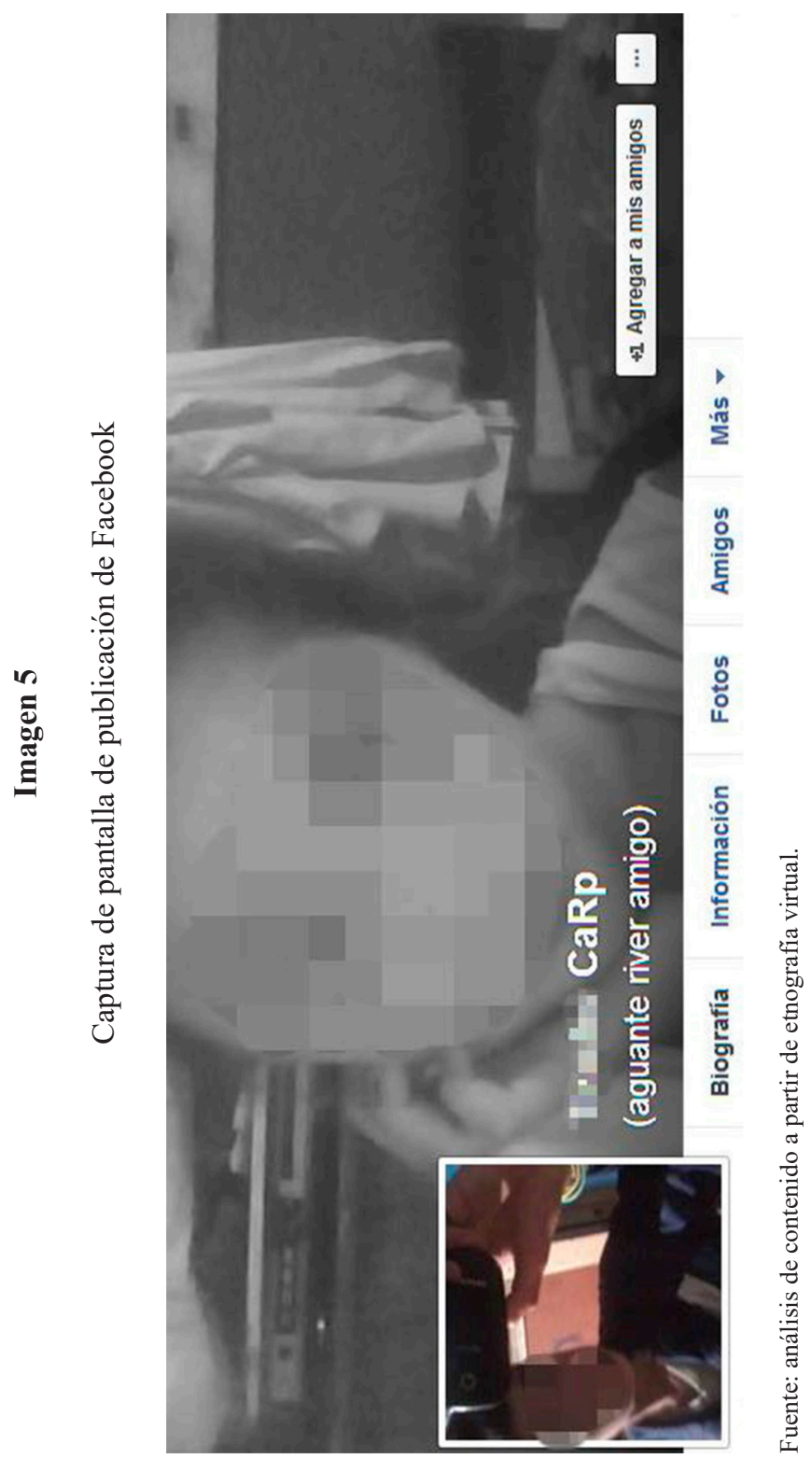


fea". Esta publicación tuvo una alta aceptación, dado que obtuvo más de cien "me gusta".

Estas performances que diseñan, publican, comentan y consumen de modo cotidiano dan cuenta de una nueva intimidad. La esfera de la intimidad

\section{Imagen 6}

Captura de pantalla de publicación de Facebook

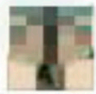

Ayer a las 1221 - le

Me muestro como soy. Cara de Noni. Feaaa. Que mas jaja?

MG \& TE FIRMO $O$

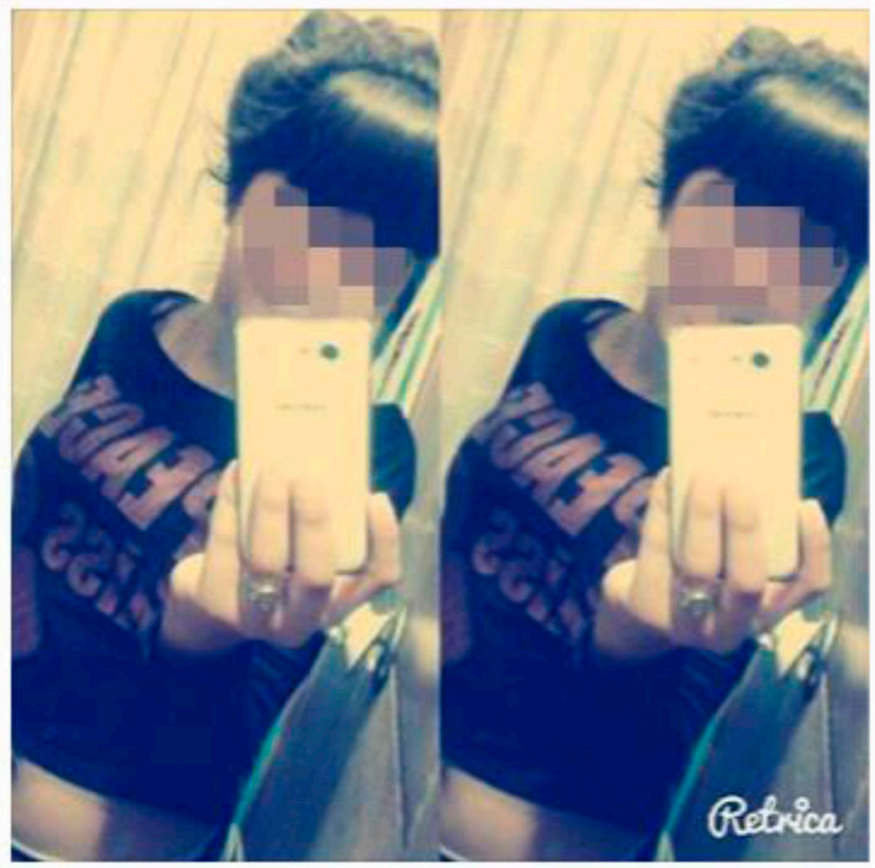

Like - Comentar - Compartir

IA y 81 personas más les gusta esto. 
se traduce públicamente en FB en escenas de performatividad, dado que para los adolescentes contemporáneos la intimidad demanda una instancia comunicativa, a diferencia del espacio acotado e interior que correspondía a su concepción tradicional. A la pregunta de cómo los adolescentes de la muestra gestionan el nivel de apertura de sus publicaciones, las siguientes respuestas resultan paradigmáticas:

\section{Entrevistas}

Publicamos fotos de salidas o de nosotros pero no las dejamos públicas para todos, sólo dejamos que las vean nuestros amigos, para no armar bardo. (Varón, 16 años)

Sacamos un montón de fotos cuando nos juntamos con amigas pero sólo elegimos algunas para Face. Y las editamos bien, tampoco da escracharse. Es importante cuidar la imagen, aunque también que sea natural, espontáneo. (Mujer, 18 años)

Como se demuestra en este artículo, tanto en el análisis de imágenes como en las voces de los entrevistados, los adolescentes de la CABA despliegan distintas estrategias para dar la mejor versión de sí mismos al autopresentarse, en parte con herramientas favorecidas por la propia plataforma, y en parte por una serie de "netiquettes"7 adquiridas mediante la experiencia y la práctica, como por ejemplo corroborar la identidad de un usuario/posible amigo a partir de su interacción en la plataforma.

Como argumenta Boyd (2014), las dinámicas comunicativas de sitios como FB han forzado a los adolescentes a modificar sus concepciones en torno a lo privado. Los planteos de esta autora contribuyen a comprender por qué entre los adolescentes existen diversos grados de apertura a las publicaciones. En suma, a lo largo de este artículo hemos aportado abundante evidencia empírica y teórica para avalar la hipótesis postulada de la "multimidad": distintos públicos acceden a diferentes performances de intimidad. En este sentido, se resalta que los adolescentes resguardan su privacidad de los otros —en especial, padres y desconocidos-, pero exhiben ciertos contenidos íntimos en FB como parte de sus performances de autopresentación.

\footnotetext{
${ }^{7}$ Este término refiere a reglas de conducta o de etiqueta digital no explicitadas en ningún reglamento pero que funcionan entre amplios grupos de internautas; por ejemplo, no publicar fotos que exhiban desnudez forma parte de la netiquette de diversos grupos de usuarios en FB.
} 


\section{Conclusiones}

En la configuración de los perfiles online de los adolescentes de la CABA son centrales las fotos personales. Las más habituales que publican los adolescentes de la muestra son las autofotos y las fotos con grupos de pares. En particular, los objetos que más se evidencian en el trabajo de campo son piercings, tatuajes, camisetas de fútbol, gorras, teléfonos móviles, cámaras de fotos, televisores, equipos de sonido, computadoras, motos y autos. Estos dispositivos funcionan como "extensiones humanas" o "prótesis" de la corporalidad, es decir, como herramientas para construir su intimidad en una sociedad en la que la configuración de lo público y lo privado se encuentra en constante cambio.

Los espacios que más fotografían suelen ser la escuela, plazas, "esquinas", centros comerciales y hogares. Las fotos publicadas funcionan como un diario íntimo de la cotidianidad que forma parte de la intimidad compartida entre pares. A través de estas imágenes personales que muestran ante su red de contactos, construyen y regulan sus intimidades mientras prueban diferentes accesorios, vestuarios y programas de edición.

En este sentido, la categoría aquí postulada de "multimidad" resulta útil porque da cuenta de las estrategias que los adolescentes realizan en FB con el fin de mostrar en red aspectos íntimos y atractivos de sí mismos. Dado que la identidad que muestran suele ser construida y ellos evidencian en las entrevistas que representan una imagen ante los otros, esta categoría permite describir analíticamente los modos en que los adolescentes exponen distintos aspectos de sí mismos en los sitios de redes sociales.

Con el concepto "multimidad" se da cuenta de los procesos a través de los cuales los adolescentes despliegan una intimidad mediante el intercambio de performances de autopresentación que incluyen aspectos íntimos. En línea con lo anterior, si los adolescentes buscan crear la mejor versión de sí mismos, no es posible pensar que su vínculo con la intimidad sea sencillamente "espontáneo". De este modo, la noción propuesta alude a una emergente intimidad múltiple entre pares construida por los adolescentes. Esta "multimidad" no es ni espectacular ni compulsiva, sino más bien un nuevo tipo de vinculación que revela nuevas configuraciones en torno a la vida pública, privada y la subjetividad.

La práctica de "producir" y compartir la intimidad refuerza, además, el argumento de que las performances de autopresentación realizadas por los adolescentes son reguladas y dadoras de sentidos. Como ha sido señalado, con este argumento se establece una distancia frente a autores que sugieren que los adolescentes utilizan las TIC sin construir sentidos ni mediacio- 
nes, y con el fin principal de exhibir su intimidad. En oposición, aquí se demuestra que los recursos desplegados por los adolescentes suelen ser meditados y forman parte de las diversas estrategias con las que construyen su front.

Recibido: febrero de 2015

Revisado: junio de 2015

Correspondencia: Neuquén 2067/CP: 1406)/Ciudad de Buenos Aires/Argentina/correo electrónico: joaquinlinne@gmail.com

\section{Bibliografía}

Ardèvol, E. y A. Estalella (2009), "Internet: instrumento de investigación y campo de estudio para la antropología visual", Revista Chilena de Antropología Visual, núm. 15, pp. 1-21.

Ardèvol, E. y G. San Cornelio (2007), "Si quieres vernos en acción: YouTube.com. Prácticas mediáticas y autoproducción en Internet", Revista Chilena de Antropología Visual, núm. 10, pp. 1-29.

Boyd, Danah (2014), It's Complicated. The Social Lives of Networked Teens, Londres y New Haven, Yale University Press.

Boyd, Danah (2008), "Why Youth Love Social Network Sites: the Role of Networked Publics in Teenage Social Life", en David Buckingham (ed.), Youth, Media and Digital Media, Cambridge, The мIт Press.

Butler, Judith (2005), Cuerpos que importan. Sobre los limites materiales y discursivos del "sexo", Buenos Aires, Paidós.

Cassell, Catherine y Gillian Symon (eds.) (1994), Qualitative Methods in Organizational Research: a Practical Guide, Londres, Sage.

Eco, Umberto (1968), Apocalípticos e integrados, Barcelona, Lumen.

Farquhar, Lee (2012), "Performing and Interpreting Identity through Facebook Imagery", Convergence, vol. 4, núm. 19, pp. 446-471.

Farquhar, Lee (2009), Identity Negotiation on Facebook.com, Iowa, University of Iowa, tesis de doctorado, en URL: http://ir.uiowa.edu/cgi/viewcontent. cgi?article $=1474 \&$ context $=$ etd, fecha de consulta enero de 2015 .

Goffman, Erving (1959), The Presentation of Self in Everyday Life, Nueva York, Anchor Books.

Hine, Christine (2000), Virtual Etnography, Londres, Sage.

INDEC (Instituto Nacional de Estadística y Censo) (2012), Encuesta nacional sobre el acceso y uso de las tecnologías de la información y la comunicación (TIC), Buenos Aires, INDEC.

INDEC (Instituto Nacional de Estadística y Censo) (2010), Censo nacional de población, Buenos Aires, INDEC. 
Linne, Joaquín (2015), Autopresentación, amistad y vínculos sexo-afectivos en sitios de redes sociales en adolescentes de sectores populares de la Ciudad de Buenos Aires, Buenos Aires, Facultad de Ciencias Sociales-Universidad de Buenos Aires, tesis de doctorado, no publicado.

Linne, Joaquín (2014), "Usos comunes de Facebook en adolescentes de distintos sectores sociales”, Comunicar, núm. 43, pp. 189-197.

Linne, Joaquín y Diego Basile (2014), "Performances de autopresentación a través de fotografías digitales. El caso de los adolescentes de sectores populares en Facebook", Cuadernos.Info, núm. 35, pp. 209-217.

Lins de Almeida, Danielle (2014), "Sobre auto-representação em imagens do Facebook. Aspectos da cultura de gênero brasileira", Revista L.I.S. (Letra. Imagen. Sonido), núm. 12, pp. 151-165.

Mayans i Planells, J. (2002), Género chat. O cómo la etnografía puso un pie en el ciberespacio, Barcelona, Gedisa.

McDermott, Elizabeth y Katrina Roen (2012), "Youth on the Virtual Edge: Researching Marginalized Sexualities and Genders Online", Qualitative Health Research, vol. 22, núm. 4, abril, pp. 560-570.

Morduchowicz, Roxana (2012), Los adolescentes y las redes sociales, Buenos Aires, FCE.

Moya, Marian y Jimena Vázquez (2010), "De la cultura a la cibercultura: la mediatización tecnológica en la construcción de conocimiento y en las nuevas formas de sociabilidad", Cuadernos de Antropología Social, núm. 31, pp. 75-96.

Murthy, Dhiraj (2008), "Social Research Digital Ethnography: an Examination of the Use of New Technologies for Social Research”, Sociology, núm. 42, vol. 5, pp. 837-855.

Pedroni, Marco, Francesa Pasquali y Simone Carlo (2014), "My Friends Are my Audience: Mass-mediation of Personal Content and Relations in Facebook", Observatorio (OBS*) Journal, vol. 3, núm. 8, pp. 97-113.

Sassen, Saskia (2002), "Towards a Sociology of Information Technology", Current Sociology, vol. 3, núm. 50, pp. 365-388.

Sibilia, Paula (2008), La intimidad como espectáculo, Buenos Aires, FCE.

Turkle, Sherry (1995), Life on the Screen: Identity in the Age of the Internet, Nueva York, Simon \& Shuster.

Urresti, Marcelo (2012), "Las cuatro pantallas y las generaciones jóvenes", en Alejandro Artopoulos (ed.), La sociedad de las cuatro pantallas. Una mirada latinoamericana, Ariel, Buenos Aires, pp. 3-29.

Urresti, Marcelo, Joaquín Linne y Diego Basile (2015), Conexión total. Los jóvenes y la experiencia social en la era de la comunicación digital, Buenos Aires, Grupo Editor Universitario. 


\section{Acerca del autor}

Joaquín Linne es doctor en ciencias sociales y docente universitario por la Universidad de Buenos Aires y la Universidad Nacional de Lanús, así como becario posdoctoral del Consejo Nacional de Investigaciones Científicas y Técnicas de Argentina (CONICET). Sus áreas de interés son sociología, tecnología, comunicación, juventud, género y política pública. Algunas de sus últimas publicaciones son, en coautoría con Marcelo Urresti y Diego Basile, Conexión total. Los jóvenes y la experiencia social en la era de la comunicación digital, Buenos Aires, Grupo Editor Universitario, 2015; y "Usos comunes de Facebook en adolescentes de distintos sectores sociales de la Ciudad de Buenos Aires", Comunicar, vol. 22, núm. 43, 2014, pp. 189-197. 